\title{
Effects of Influent Algae Concentrations and Seasonal Variations on Pollutant Removal Performance in High-Rate Algae Ponds
}

\author{
Yi Ding ${ }^{1,2}$, Xinshan Song², Wei Wang ${ }^{2}$, Yuhui Wang'* \\ 'College of Ocean Science and Engineering, Center for Marine Environmental and Ecological Modelling, \\ Shanghai Maritime University, Shanghai 201306, China \\ ${ }^{2}$ College of Environmental Science and Engineering, State Environmental Protection Engineering Center for Pollution \\ Treatment and Control in the Textile Industry, Donghua University, Shanghai 201620, China
}

Received: 22 July 2017

Accepted: 3 September 2017

\begin{abstract}
Algae can increase $\mathrm{pH}$ and dissolved oxygen via photosynthesis and affect the wastewater treatment performance of high-rate algae ponds (HRAPs). Nine laboratory-scale HRAPs divided into three groups were constructed to treat synthetic wastewater via six-month experiments. Higher algae concentrations in the influent of HRAPs effectively promoted the wastewater treatment performance. Seasonal variation had a significant impact on algal growth. Summer tests exhibited a higher reduction of pollutants than autumn tests. The high-influent algae concentration group in summer (HRAP-A) largely reduced the TN by $52.7 \pm 3.0 \%$, TP by $90.3 \pm 1.0 \%$, and dissolved chemical oxygen demand (DCOD) by $99.0 \pm 1.0 \%$. It outperformed the low influent algae concentration group in summer (HRAP-B) and was significantly higher than the high influent algae concentration group in autumn (HRAP-C). The appropriate operation and design of HRAPs contributed to efficient wastewater treatments.
\end{abstract}

Keywords: high-rate algae pond, influent algae concentration, seasonal variation, wastewater treatment

\section{Introduction}

The rapid development of global industrialization has aggravated nutrients and organic matters into the water system [1-2]. The uncontrolled disposal of domestic and industrial wastewaters into the environment causes severe pollution problems such as eutrophication or oxygen depletion in lakes and rivers [3-4]. Multipollutants should be removed before treated effluents are

*e-mail: yhwang@dhu.edu.cn discharged or reused. In recent decades, conventional wastewater treatment technologies such as stabilization ponds, aerobic activated sludge processes, and anaerobic digestion have been widely used. However, these systems usually are characterized by high energy consumption and large land areas [5]. To save much land and produce qualified treated effluent, it is critical to develop a compact and economical wastewater treatment system [6].

Microalgae-based wastewater treatment technologies such as high-rate algae ponds (HRAPs) have received considerable attention in recent years for biofuel production and a high-quality effluent as microalgae own the ability to grow on wastewater and have high 
photosynthetic efficiency [7-8]. Algae can increase pH and dissolved oxygen (DO) via photosynthesis in HRAP, which is attributed to phosphorus precipitation and aerobic degradation of organic compounds. In addition, ammonia and phosphate in wastewater may be nutrient sources for algae [9]. HRAPs offer more efficient wastewater treatment than conventional technologies through algal growth and photosynthetic aeration, and overcome their drawbacks such as poor and highly variable effluent quality, limited nutrients, and organics removal [7]. For instance, aeration in an activated sludge wastewater treatment plant is a costly process and represents 45 $75 \%$ of energy consumption [10]. However, HRAPs for wastewater treatment are economical because they use microalgae to produce the oxygen, which is subsequently used by bacteria to biodegrade hazardous pollutants. Photosynthetic aeration is therefore especially important in reducing operational costs [11].

Even though the HRAPs represent a very consolidated technology, there are several ways to optimize their operation toward increasing biomass production and multi-pollutant removal. HRAP performance depends on algal biomass, which is mainly affected by influent algae concentration and seasonal variation. However, the effects of influent algae concentration or seasonal variation on algal growth and pollutant removal in HRAPs have not yet been thoroughly studied. In addition, insufficient knowledge about the algal photosynthetic activity impedes the design and development of HRAPs. The study aims to evaluate algal photosynthetic activity in summer and autumn under different influent algae concentrations and discuss the effects of influent algae concentration and season variation (summer and autumn) on algal growth and pollutant removal in HRAPs.

\section{Material and Methods}

The algae (Microcystis aeruginosa) from Freshwater Algae Culture Collection at the Institute of Hydrobiology, FACHB-Collection (Wuhan, China) were cultured and enriched in a laboratory with BG culture medium [12] and tap water. The cultivation parameters are provided as follows: air temperature of $25-35^{\circ} \mathrm{C}$ (Air Quality Measure Meter, Pranus, China), relative humidity of 70-85\% (Air Quality Measure Meter, Pranus, China), and daylight illumination intensity of 5,000-8,000 lux (Manta 2 water quality multi-probe, EURERA, USA).

Experiments were performed for six months (June to November 2014) in Donghua University, Shanghai, China $\left(38^{\circ} 39^{\prime} 27.97^{\prime \prime} \mathrm{N}-104^{\circ} 04^{\prime} 58.66^{\prime \prime} \mathrm{E}\right)$. Nine identical lab-scale HRAPs $(0.96 \times 0.60 \times 0.60 \mathrm{~m})$ were built outdoors for the experiments and the effective volume was $0.32 \mathrm{~m}^{3}$. Each HRAP consisted of a mechanical stirrer and a single-loop raceway separated by a central baffle. Each pond was circulated at a surface velocity of $0.15 \pm 0.03 \mathrm{~m} / \mathrm{s}$ under the drive of a mechanical stirrer. Influent tube and effluent tube were respectively arranged on the two sides of each pond. The HRAPs received synthetic wastewater from influent tanks (300 L) via peristaltic pumps. The HRAPs were operated intermittently and hydraulic retention time (HRT) was $3 \mathrm{~d}$. Daytime included HRT ranging from 0 to $12 \mathrm{~h}, 24$ to $36 \mathrm{~h}$, and 48 to $60 \mathrm{~h}$, while nighttime included HRT ranging from 12 to $24 \mathrm{~h}, 36$ to $48 \mathrm{~h}$, and 60 to $72 \mathrm{~h}$. Synthetic wastewater was added into HRAPs by using a peristaltic pump at a stable inflow rate of $4.0 \pm 0.2 \mathrm{~L} \mathrm{~min}^{-1}$. The total inflow was $250 \pm 5 \mathrm{~L}$ within $1 \mathrm{~h}$.

The experimental period was divided two phases: summer months (June to August) and autumn months (September to November). Temperature ranges in summer tests and autumn tests were $25-35^{\circ} \mathrm{C}$ and $10-20^{\circ} \mathrm{C}$, respectively. Nine ponds were divided into three groups: the high-influent algae concentration group in summer months (HRAP-A), the low-influent algae concentration group in summer months (HRAP-B), and the highinfluent algae concentration group in autumn months (HRAP-C). Each group contained three replicates.

Nitrogen, phosphate, and organics were added in the form of $\mathrm{NH}_{4} \mathrm{Cl}, \mathrm{KH}_{2} \mathrm{PO}_{4}$, and glucose to achieve total nitrogen (TN) of $23.5 \pm 0.8 \mathrm{mg} / \mathrm{L}$, total phosphate (TP) of $4.65 \pm 0.2 \mathrm{mg} / \mathrm{L}$, and dissolved chemical oxygen demand (DCOD) of $75 \pm 4 \mathrm{mg} / \mathrm{L}$. In addition, trace elements were added to match the constituents found in wastewater. The dissolved oxygen (DO) concentrations in the influent in HRAP-A, HRAP-B, and HRAP-C were $5.95 \pm 0.5 \mathrm{mg} / \mathrm{L}$, $4.25 \pm 0.5 \mathrm{mg} / \mathrm{L}$, and $4.74 \pm 0.5 \mathrm{mg} / \mathrm{L}$, respectively. The $\mathrm{pH}$ values in the influent in HRAP-A, HRAP-B, and HRAP-C were $8.11 \pm 0.1, \quad 7.58 \pm 0.1$, and $7.60 \pm 0.1$, respectively. The algae concentrations in HRAP-A, HRAP-B, and HRAP-C were adjusted to 2,989 $\pm 200,537 \pm 200$, and $2,783 \pm 200$ cells $\cdot \mathrm{mL}^{-1}$ by adding appropriate amounts of algal solution into synthetic wastewater.

Water samples were collected from the effluent at $6 \mathrm{~h}$, 12 h, 24 h, 30 h, 36 h, 48 h, 54 h, 60 h, and 72 h to evaluate the algal photosynthetic activity and pollutant removals of the three groups. Samples were tested in triplicate. Water temperature, $\mathrm{pH}$, and $\mathrm{DO}$ in influent and effluent were measured with a DO meter (HI 9143, HANNA, Italy) and pH meter (HI 9125, HANNA, Italy) immediately after sampling. Algae concentrations in influent and effluent were measured with a water quality multi-probe (Manta 2, EURERA, USA). Dissolved chemical oxygen demand (DCOD), TN, and TP in influent and effluent were measured with the multi-parameter colorimeter (DR900, $\mathrm{HACH}, \mathrm{USA}$ ). To avoid the influence of dead algae and algal debris on the determination of DCOD, the samples were filtered through Whatman $\mathrm{GF} / \mathrm{C}$ glass-fiber filters $(0.22 \mu \mathrm{m})$ before DCOD determination.

Measurement data were analyzed and plotted with the statistical functions of Origin 8.0 software (OriginLab, MA, USA). All data were expressed as mean \pm SD. Statistical analyses were performed by Student's t-test at the significant level of 0.01 . 


\section{Results and Discussion}

Fig. 1 shows the variations of algae concentration, DO, and $\mathrm{pH}$ in HRAPs. As shown in Fig. 1a), the algae concentration in summer tests (HRAP-A and HRAP-B) is higher than that in autumn tests (HRAP-C). Algae concentration gradually increased with HRT in HRAPs. However, algae concentration in HRAP-A was higher than that in HRAP-B due to the difference in influent algae concentration. Influent algae concentration had a positive effect on algal growth through influencing water quality condition by photosynthesis. During the initial stage (0-24 h) of summer tests, algae grew slowly before adaptation. With the extension of HRT, algae growth went into the rapid phase for full adsorption of nutrients in influents. Appropriate illumination and temperature in summer created favorable conditions for algal growth. The maximum algae concentration reached $27,545 \pm 200$ and $23,957 \pm 200$ cells $\cdot \mathrm{mL}^{-1}$ after 60 -h HRT in HRAP-A and HRAP-B, respectively. In the final stage (60-72 h) of summer tests, the algal amount decreased due to competitive growth and nutrient deficiency.

During the autumn tests, algae grew slowly and the maximum algae concentration reached $11,305 \pm 200$ cells $\cdot \mathrm{mL}^{-1}$ after 60 -h HRT in HRAP-C. The peak value

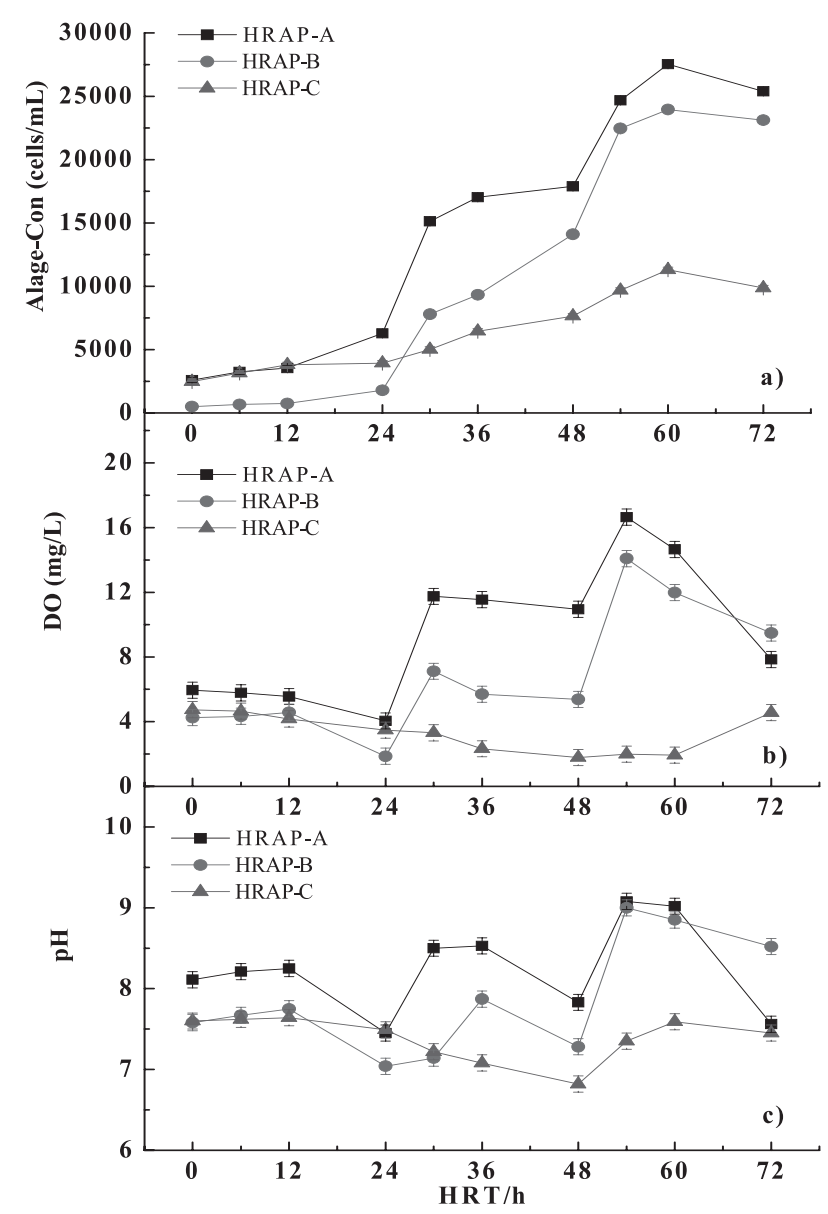

Fig. 1. Profiles of algae concentration a), $\mathrm{DO}$ b) and $\mathrm{pH}$ c) in HRAPs. of algae concentration in HRAP-C was significantly lower than that in HRAP-A and HRAP-B $(p<0.01)$. This phenomenon could be explained in two aspects. Firstly, the low temperature in autumn was not conducive to algal growth. Secondly, in autumn the light supply period was short and the light intensity was weak, thus negatively affecting algal photosynthesis.

The autumn tests and summer tests showed significant differences in DO profile throughout the experimental period ( $p<0.01$; Fig. 1b). The main reason was that low temperature conditions in autumn tests affected the algal photosynthesis and growth in HRAPs. In general, DO value increased due to algal photosynthesis in the daytime, whereas it decreased due to algal and bacterial respiration in the nighttime. During 1-d HRT of summer tests DO content in HRAP-A and HRAP-B showed no significant change. This phenomenon could be explained by the fact that algal growth went through the stationary phase in which algal metabolic activity was slow. With the extension of HRT, the growing amount of algae facilitated algal photosynthesis and DO content in both HRAPs significantly increased. The maximum daytime DO in HRAP-A and HRAP-B reached $16.65 \pm 0.5 \mathrm{mg} / \mathrm{L}$ and $14.08 \pm 0.5 \mathrm{mg} / \mathrm{L}$ around midday, respectively. In the DO profiles of HRAP-A and HRAP-B, DO value in HRAP-A was higher than that in HRAP-B due to the larger algae amount in HRAP-A.

Fig. 1c) presents the profile of $\mathrm{pH}$ in HRAPs. The autumn tests and summer tests showed significant differences in $\mathrm{pH}$ profile $(p<0.01)$. During summer tests, daytime $\mathrm{pH}$ value increased due to algal photosynthesis in HRAP-A and HRAP-B. The maximum daytime $\mathrm{pH}$ in HRAP-A and HRAP-B reached $9.1 \pm 0.1$ and $9.0 \pm 0.1$ around midday, respectively. During summer tests, nighttime $\mathrm{pH}$ value decreased due to algal and bacterial respiration in both HRAPs. The minimum nighttime $\mathrm{pH}$ in HRAP-A and HRAP-B reached $7.45 \pm 0.1$ and $7.04 \pm 0.1$ before sunrise, respectively. Algal photosynthesis was enhanced with the increase in the algae amount in HRAPs, thus leading to the increase of $\mathrm{pH}$ value. The $\mathrm{pH}$ value in HRAP-A was higher than that in HRAP-B due to the higher algae concentration in the influents.

Ammonia and phosphate may be nutrient sources for algae [8]. Nitrogen assimilation by algal cells represents the direct nitrogen removal mechanism in the HRAPs [13]. Elevated daytime $\mathrm{pH}(>9.0)$ in the HRAPs by algal photosynthesis results in ammonia volatilization, causing indirect nitrogen removal [14]. Therefore, algal growth and photosynthesis can have a major influence on nitrogen reduction in HRAP. The variations of TN, TP, and DCOD in effluents with HRT are shown in Fig. 2. As shown in Fig. 2a), reductions in TN were more significant in HRAP-A and HRAP-B $(p<0.01)$, where the algae biomass was the most abundant. When the HRT was $72 \mathrm{~h}$, the TN in the effluent in HRAP-A was $10.9 \pm 0.8 \mathrm{mg} / \mathrm{L}$, which was lower than that (12.5 mg/L) in HRAP-B. After 72-h HRT, TN removal in the influent of HRAP-A and HRAP-B were $52.7 \pm 3.0 \%$ and $45.7 \pm 3.0 \%$, respectively. The higher 


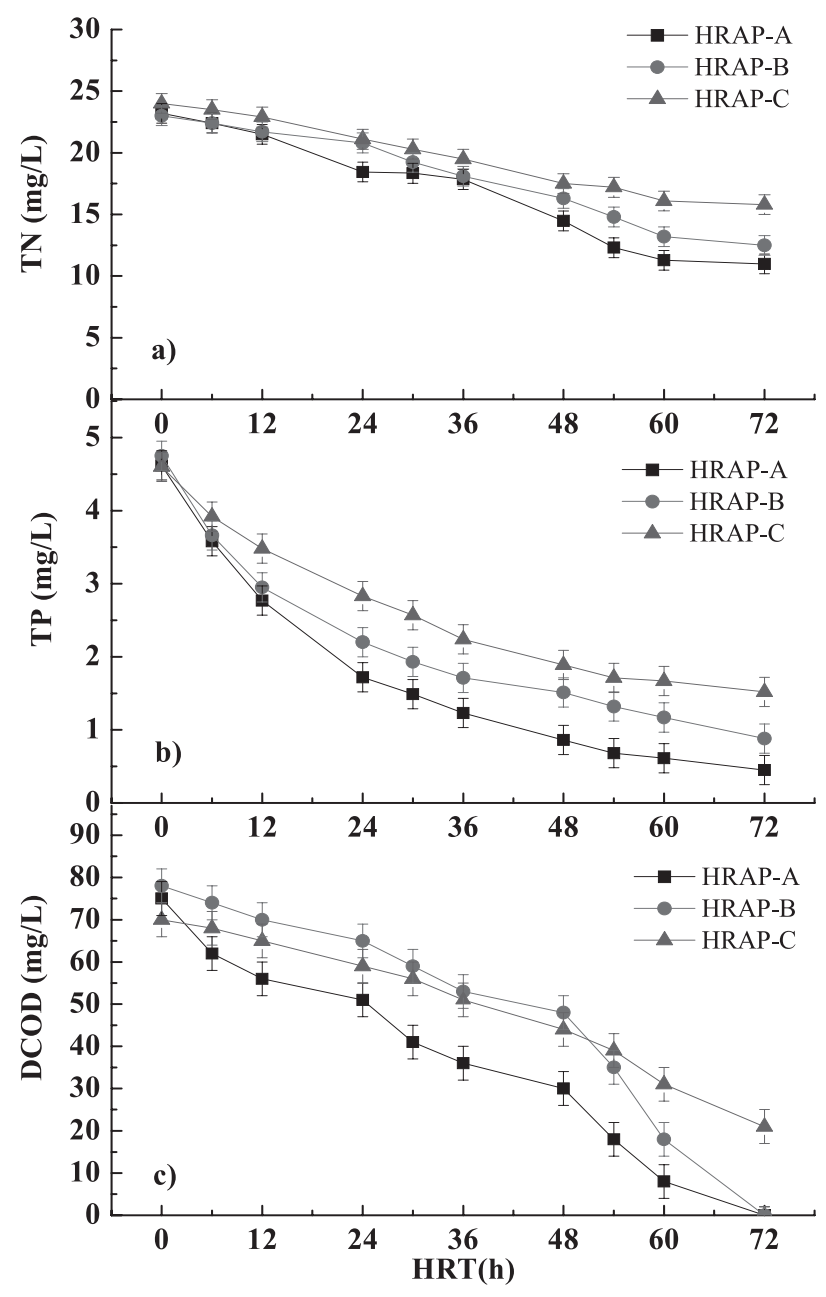

Fig. 2. Profiles of TN a), TP b) and DCOD c) in HRAPs.

algae concentration in the influent in HRAP-A effectively increased the algal growth and amount, which facilitated the nitrogen assimilation by algal cells. HRAP-C showed lower TN removal $(34.2 \pm 3.0 \%)$ in autumn months and the $\mathrm{TN}$ in the effluent in HRAP-C was $15.8 \pm 0.8 \mathrm{mg} / \mathrm{L}$. The activity and growth of algae in HRAP-C was restrained by the unfavorable conditions in autumn months, thus decreasing TN removal.

Phosphorus in HRAPs was usually removed by algae uptake and the immobilization in the sediment by precipitation of iron or calcium-bound phosphorus [15]. The main process for phosphorus removal was achieved by precipitation of calcium phosphate at high $\mathrm{pH}(>8.0)$ in HRAPs [16]. Table 1 presents the correlations between daytime $\mathrm{pH}$ variation and TP removal in HRAPs. The $\mathrm{pH}$ value increased in daytime due to algal photosynthesis. In daytime, the $\mathrm{pH}$ value in HRAP-A was higher than that in HRAP-B, thus facilitating phosphorus removal via chemical precipitation. At the daytime of day 3, the optimal TP removal in HRAP-A reached $86.8 \pm 1.0 \%$, which was significantly higher than in HRAP-B $(75.4 \pm 1.0 \% ; p<0.01)$. Compared with summer tests, the lower TP removal $(63.7 \pm 1.0 \%)$ was observed in HRAP-C due to the low $\mathrm{pH}$ in autumn affected by the unfavorable algal photosynthesis.
Table 1. Correlations between daytime $\mathrm{pH}$ variation and TP removal in HRAPs (a indicates HRT of $12 \mathrm{~h}, \mathrm{~b}$ indicates HRT of $36 \mathrm{~h}$, and $\mathrm{c}$ indicates HRT of $60 \mathrm{~h}$ ).

\begin{tabular}{|c|c|c|c|}
\hline \multirow{3}{*}{ Groups } & $\begin{array}{c}\text { Daytime } \\
(\mathrm{h})\end{array}$ & $\begin{array}{c}\text { Ranges of } \\
\mathrm{pH}\end{array}$ & $\begin{array}{c}\text { Optimal TP } \\
\text { removal (\%) }\end{array}$ \\
\hline \multirow{3}{*}{ HRAP-A } & $0-12$ & $8.11-8.25$ & $40.0 \pm 1.0^{\mathrm{a}}$ \\
\cline { 2 - 4 } & $24-36$ & $7.45-8.53$ & $73.4 \pm 1.0^{\mathrm{b}}$ \\
\cline { 2 - 4 } & $48-60$ & $7.83-9.08$ & $86.8 \pm 1.0^{\mathrm{c}}$ \\
\hline \multirow{3}{*}{ HRAP-B } & $0-12$ & $7.58-7.75$ & $37.9 \pm 1.0^{\mathrm{a}}$ \\
\cline { 2 - 4 } & $24-36$ & $7.04-7.87$ & $64.0 \pm 1.0^{\mathrm{b}}$ \\
\cline { 2 - 4 } & $48-60$ & $7.28-9.00$ & $75.4 \pm 1.0^{\mathrm{c}}$ \\
\hline & $0-12$ & $7.60-7.64$ & $24.3 \pm 1.0^{\mathrm{a}}$ \\
\cline { 2 - 4 } & $24-36$ & $7.08-7.49$ & $51.3 \pm 1.0^{\mathrm{b}}$ \\
\cline { 2 - 4 } & $48-60$ & $6.82-7.59$ & $63.7 \pm 1.0^{\mathrm{c}}$ \\
\hline
\end{tabular}

The variations of TP in experimental groups are shown in Fig. 2b). HRAP-A and HRAP-B, respectively, showed the better TP removal performances of $90.3 \pm 1.0 \%$ and $81.5 \pm 1.0 \%$ after 72 -h HRT. The TP in the effluent of HRAP-A was $0.45 \pm 0.2 \mathrm{mg} / \mathrm{L}$, which was lower than that $(0.88 \pm 0.2 \mathrm{mg} / \mathrm{L})$ in HRAP-B. The higher algae concentration in the influent of HRAP-A effectively promoted the algal growth activity and photosynthesis, which facilitated the phosphorus assimilation by algal cells and phosphorus precipitation at high $\mathrm{pH}$ in summer. HRAP-C showed the lower TN removal $(67.0 \pm 1.0 \%)$ in autumn months and the TP of the effluent in HRAP-C was $1.52 \pm 0.2 \mathrm{mg} / \mathrm{L}$. TP removal in HRAP-C was significantly lower than that in both HRAP-A and HRAP-B $(p<0.01)$.

Algae can increase dissolved oxygen concentrations in the treated effluent by photosynthesis and affect the DCOD removal from wastewater by providing $\mathrm{O}_{2}$ to the heterotrophic aerobic bacteria in HRAPs [11]. Table 2

Table 2. Correlations between daytime DO variation and DCOD removal in HRAPs (a indicates HRT of $12 \mathrm{~h}, \mathrm{~b}$ indicates HRT of $36 \mathrm{~h}$, and $\mathrm{c}$ indicates HRT of $60 \mathrm{~h}$ ).

\begin{tabular}{|c|c|c|c|}
\hline \multirow{3}{*}{ Groups } & $\begin{array}{c}\text { Daytime } \\
(\mathrm{h})\end{array}$ & $\begin{array}{c}\text { Ranges } \\
\text { of DO }\end{array}$ & $\begin{array}{c}\text { Optimal DCOD } \\
\text { removal (\%) }\end{array}$ \\
\hline \multirow{3}{*}{ HRAP-A } & $0-12$ & $5.55-5.95$ & $25.3 \pm 2.0^{\mathrm{a}}$ \\
\cline { 2 - 4 } & $24-36$ & $4.05-11.55$ & $52.0 \pm 2.0^{\mathrm{b}}$ \\
\cline { 2 - 4 } & $48-60$ & $10.95-16.65$ & $89.3 \pm 2.0^{\mathrm{c}}$ \\
\hline \multirow{3}{*}{ HRAP-B } & $0-12$ & $4.25-4.58$ & $10.3 \pm 2.0^{\mathrm{a}}$ \\
\cline { 2 - 4 } & $24-36$ & $1.86-7.12$ & $32.1 \pm 2.0^{\mathrm{b}}$ \\
\cline { 2 - 4 } & $48-60$ & $5.38-14.08$ & $76.9 \pm 2.0^{\mathrm{c}}$ \\
\hline & $0-12$ & $4.17-4.74$ & $7.2 \pm 2.0^{\mathrm{a}}$ \\
\cline { 2 - 4 } & $24-36$ & $2.32-3.48$ & $27.1 \pm 2.0^{\mathrm{b}}$ \\
\cline { 2 - 4 } & $48-60$ & $1.78-1.99$ & $55.7 \pm 2.0^{\mathrm{c}}$ \\
\hline
\end{tabular}


presents the correlations between daytime DO variation and DCOD removal in HRAPs. DO content increased in daytime due to algal photosynthesis. With the extension of HRT, the mean DO concentration in daytime in HRAP-A was higher than that in HRAP-B, thus facilitating aerobic degradation of organic compounds. The DO range was higher in algae-abundant HRAPs due to efficient photosynthesis. In the daytime of day 3 the optimal DCOD removal in HRAP-A reached $89.3 \pm 2.0 \%$, which was significantly higher than that in HRAP-B $(76.9 \pm 2.0 \% ; p<0.01)$. Compared with summer tests, the lower DCOD removal $(55.7 \pm 2.0 \%)$ was observed in HRAP-C due to the low DO in autumn affected by the inefficient algal photosynthesis.

The variations of DCOD in experimental groups are shown in Fig. 2c). DCOD in the effluent in HRAP-A and HRAP-B sharply declined, whereas DCOD in the effluent in HRAP-C declined gradually. The DCOD in the effluent in HRAP-A and HRAP-B could hardly be detected and was significantly lower than that in HRAP-B $(21 \pm 4 \mathrm{mg} / \mathrm{L}$; $p<0.01)$. The removal of DCOD in both HRAP-A and HRAP-B after 72-h HRT was over 99.0\%, which was significantly higher than that in HRAP-C $(70.0 \pm 2.0 \%$; $p<0.01$ ). Sufficient $\mathrm{O}_{2}$ was conducive to the aerobic degradation of DCOD in HRAPs. The low temperature and deficiency of light supply in autumn impeded algal growth activity, thus influencing algae photosynthesis and leading to poor DCOD removal.

\section{Conclusions}

The algae amount in HRAPs contributes to the increase of $\mathrm{pH}$ and $\mathrm{DO}$ via photosynthesis. Influent algae concentration had a positive effect on algal growth and metabolism. The higher algae concentration in the influent effectively promoted growth and quantity. The higher algae concentration was obtained in summer tests (HRAP-A and HRAP-B) compared to autumn tests (HRAP-C). The better contaminant removal performance was obtained in HRAP-A for the favorable temperature and the large algae amount, which led to the optimal removal of TN, TP, and DCOD.

\section{Acknowledgements}

This study was supported by the National Key Technology Support Program (grant No. 2015BAB07B00), the National Natural Science Foundation of China (grant Nos. 51309053 and 51679041) and the Fundamental Research Funds for the Central Universities (grant Nos. 15D211302 and 16D311302).

\section{References}

1. ABNANDAN S., SHANTHAKUMAR S. Challenges and opportunities in application of microalgae (Chlorophyta) for wastewater treatment: A review. Renew. Sust. Energ. Rev., 52, 123, 2015.

2. KONG Q.X., LI L., MARTINEZ B., CHEN P., RUAN R. Culture of algae Chlamydomonas reinhardtii in wastewater for biomass feedstock production. Appl. Biochem. Biotech., 160 (1), 9, 2010.

3. CAI T., PARK S.Y., LI Y. Nutrient recovery from wastewater streams by microalgae: Status and prospects. Renew. Sust. Energ. Rev., 19 (1), 360, 2013.

4. ZHANG S.-Y., ZHOU Q.-H., XU D., HE F., CHEN S.-P., LIANG W., DU C., WU Z.-B. Vertical-flow constructed wetlands applied in a recirculating aquaculture system for channel catfish culture: effects on water quality and zooplankton. Polish J. of Environ. Stud., 19 (5), 1063, 2010.

5. POSADAS E., GARCÍA-ENCINA P.-A., SOLTAU A., DOMÍNGUEZ A., DÍAZ I., MUNOZ R. Carbon and nutrient removal from centrates and domestic wastewater using algal-bacterial biofilm bioreactors. Bioresour. Technol., 139 (13), 50, 2013.

6. BABU M.A., VAN DER STEEN N.P., HOOIJMANS C.M., GIJZEN H.J. Nitrogen mass balances for pilot-scale biofilm stabilization ponds under tropical conditions. Bioresour. Technol., 102 (4), 3754, 2011.

7. CRAGGS R., SUTHERLAND D., CAMPBELL H. Hectare-scale demonstration of high rate algal ponds for enhanced wastewater treatment and biofuel production. J. Appl. Phycol., 24 (3), 329, 2012.

8. MEHRABADI A., CRAGGS R., FARID M.M. Wastewater treatment high rate algal ponds (WWT HRAP) for low-cost biofuel production. Bioresour. Technol., 184, 202, 2015.

9. MA X.C., ZHOU W.G., FU Z.Q., CHENG Y.L., MIN M., LIU Y.H., ZHANG Y.K., CHEN P., RUAN R. Effect of wastewater-borne bacteria on algal growth and nutrients removal in wastewater-based algae cultivation system. Bioresour. Technol., 167, 8, 2014.

10. KARYA N.G.A.I., VAN DER STEEN N.P., LENS P.N.L. Photo-oxygenation to support nitrification in an algalbacterial consortium treating artificial wastewater. Bioresour. Technol., 134 (2), 244, 2013.

11. MUNOZ R., GUIEYSSE B. Algal-bacterial processes for the treatment of hazardous contaminants: A review. Water Res., 40 (15), 2799, 2006.

12. KESAANO M., SIMS R.C. Algal biofilm based technology for wastewater treatment. Algal Res., 5 (1), 231, 2014.

13. GARCÍA J., MUJERIEGO R., HERNÁNDEZ-MARINÉ M. High rate algal pond operating strategies for urban wastewater. J. Appl. Phycol., 12 (3-5), 331, 2000.

14. PARK J.B.K., CRAGGS R.J. Nutrient removal in wastewater treatment high rate algal ponds with carbon dioxide addition. Water Sci. Technol., 63 (8), 1758, 2011.

15. KIM B.H., KANG Z., RAMANAN R., CHOI J.E., CHO D.H., OH H.M., KIM H.S. Nutrient removal and biofuel production in high rate algal pond using real municipal wastewater. J. Microbiol. Biotechnol., 24 (8), 1123, 2014.

16. PICOT B., EL HALOUANI H., CASELlAS C., MOERSIDIK S., BONTOUX J. Nutrient removal by high rate pond system in a Mediterranean climate (France). Water Sci. Technol., 23 (7-9), 1535, 1991. 
